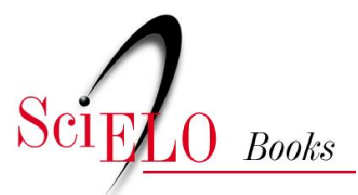

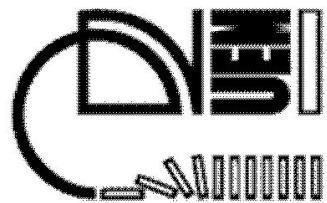

\title{
Discurso e biopolítica na sociedade de controle
}

\author{
Kátia Menezes de Sousa
}

SciELO Books / SciELO Livros / SciELO Libros

SOUSA, KM. Discurso e biopolítica na sociedade de controle. In TASSO, I., and NAVARRO, P., orgs. Produção de identidades e processos de subjetivação em práticas discursivas [online]. Maringá: Eduem, 2012. pp. 41-55. ISBN 978-85-7628-583-0. Available from SciELO Books

$<$ http://books.scielo.org $>$.

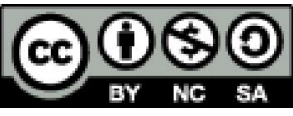

All the contents of this chapter, except where otherwise noted, is licensed under a Creative Commons Attribution-Non Commercial-ShareAlike 3.0 Unported.

Todo o conteúdo deste capítulo, exceto quando houver ressalva, é publicado sob a licença Creative Commons Atribuição Uso Não Comercial - Partilha nos Mesmos Termos 3.0 Não adaptada.

Todo el contenido de este capítulo, excepto donde se indique lo contrario, está bajo licencia de la licencia Creative Commons Reconocimento-NoComercial-CompartirIgual 3.0 Unported. 


\section{DISCURSO E BIOPOLÍTICA NA SOCIEDADE DE CONTROLE}

Kátia Menezes de Sousa ${ }^{7}$

A arqueologia de Michel Foucault é uma modalidade de análise do discurso. Conforme o autor (1995), o discurso é constituído por um conjunto de sequências de signos enquanto enunciados, isto é, enquanto se lhes possam atribuir modalidades particulares de existência por terem sido efetivamente produzidas. $\mathrm{O}$ enunciado se refere ao que realmente pôde ser dito; é constituído por uma materialidade que lhe dá substância, suporte, lugar e uma temporalidade que lhe asseguram uma identidade. Além disso, possui um valor que caracteriza o lugar em que aparece, a sua capacidade de circulação e de troca, sua possibilidade de transformação na administração de seus raros recursos e de sua pobreza enunciativa. Soma-se a isso o fato de que o enunciado porta uma exterioridade paradoxal e formas de acúmulo que garantem os jogos da memória e do esquecimento. É por isto que o discurso, assim concebido,

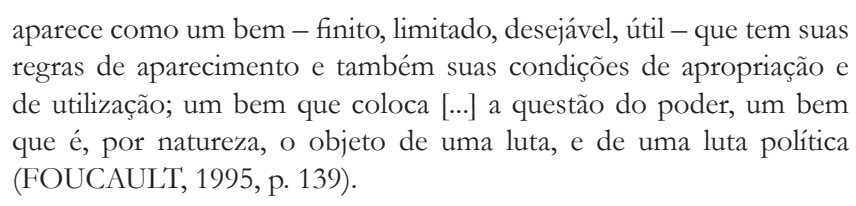
regras de aparecimento e também suas condições de apropriação e de utilização; um bem que coloca [...] a questão do poder, um bem que é, por natureza, o objeto de uma luta, e de uma luta política (FOUCAULT, 1995, p. 139).

7 Professora da Faculdade de Letras e do Programa de Pós-Graduação em Letras e Linguística da Universidade Federal de Goiás. 

Pimeira parte :: Discurso biopolítica na sociedade de controle

desenhar no século XVIII, com o aparecimento de um poder que é ao mesmo tempo disciplinador e normalizador e não se exerce mais sobre os corpos individualizados, mas se concentra na figura do Estado, em que é exercido com pretensões de administrar a vida e o corpo da população. No texto "A governamentalidade", parte de uma aula ministrada em 1978, Foucault (2003) explica que, após o século XVIII, a arte de governar ligou-se à emergência da expansão demográfica, e seus objetivos passaram a ser melhorar o destino das populações, aumentar a duração de sua vida e melhorar sua saúde. Os instrumentos utilizados para alcançar esses objetivos se centrarão essencialmente na própria população, sobre a qual o governo age diretamente, fazendo campanhas, ou indiretamente, estimulando, sem que as pessoas o percebam, a taxa de natalidade, ou dirigindo os fluxos populacionais para certas regiões e para dadas atividades.

Nesse sentido, é fácil perceber que na atualidade as campanhas governamentais se aprimoraram e se constituem em um eficiente meio de esclarecer e conscientizar sobre o que o governo faz e o que a população cobra e espera. As campanhas retratam a forma de governar, as vozes suplicantes da população e os problemas advindos da rapidez e globalização da circulação das informações, dos problemas que retornam e dos que persistem em continuar estampados nos enunciados dos diferentes campos do saber.

Numa conferência proferida no Rio de Janeiro em 1974, publicada em Microfísica do poder, Foucault (2003) levanta a hipótese de que o capitalismo socializou um primeiro objeto, que foi o corpo enquanto força de produção, e de que o controle da sociedade sobre os indivíduos não se operava simplesmente pela consciência ou pela ideologia, mas começava no corpo e com o corpo. Conclui afirmando que a sociedade capitalista investiu 
Produçäo de identidades e processos de subjetivaçäo em práticas discursivas

no biológico, no somático, no corporal, pois o corpo é uma realidade biopolítica, e a medicina, uma estratégia biopolítica. Mesmo por uma investigação despretensiosa, desde que de caráter científico, é possível perceber que os enunciados que compõem as plataformas políticas ou a interação dos governos com a população referem-se, sob vários aspectos, ao interior e ao exterior dos corpos das pessoas, para a garantia de saúde, bemestar, beleza e longevidade.

Em 1976 Foucault desenvolveu o conceito de biopolítica em História da sexualidade I: a vontade de saber, e nas aulas ministradas no Collège de France, publicadas mais tarde na obra Em defesa da sociedade, considerando esse conceito no interior de uma estratégia mais ampla, que ele denominou de biopoder. Conforme Foucault (2001), o biopoder sucede o poder de soberania, mantendo a relação vida/morte. Enquanto para o soberano a máxima era fazer morrer e deixar viver, para o biopoder a ordem é fazer viver e deixar morrer. A partir do século XIX a lógica deixa de ser a da soberania e passa a ser a lógica biológica. O "fazer viver" a que se refere Foucault (1999), segundo Pelbart (2003), marca o biopoder e se constitui de duas formas: como disciplina e como biopolítica. As disciplinas, baseadas no adestramento do corpo, na otimização de suas forças, na sua integração em sistemas de controle, tomam o corpo como máquina, sujeito, assim, a uma anatomopolítica. A biopolítica mobiliza outro componente estratégico, que é a gestão da vida incidir não mais sobre os indivíduos, mas sobre a população enquanto espécie. Aqui o corpo é atravessado pela mecânica do vivente, como suporte de processos biológicos. Trata-se da biopolítica da população, em que a ênfase recai sobre nascimento e mortalidade e sobre o nível de saúde e a longevidade. 
Instaura-se, assim, uma tecnologia de duas faces, a qual, na leitura de Pelbart (2003), caracteriza-se, de um lado, pelo biopoder - que se realiza por intermédio das disciplinas, das regulações e da anatomopolítica do corpo -, e por outro, pela biopolítica da população - por meio da espécie, das 'performances' do corpo e dos processos da vida. Ao lado da submissão dos corpos através das escolas, quartéis e fábricas, surgem os problemas de natalidade, longevidade, saúde pública, habitação e imigração.

Apesar de ter formulado tais conceitos ainda nos anos de 1970, o legado da reflexão de Foucault, conforme analisa Duarte (2008), vinte anos depois dissemina idéias e renova campos distintos da investigação das Ciências Humanas, promovendo a formulação de novos problemas e novas possibilidades de análise. $\mathrm{Na}$ atualidade, os conceitos de biopoder e biopolítica ganham importância capital nas análises dos problemas políticos e sociais.

Realçando sua relevância, Hardt e Negri (2004) consideram que a obra de Foucault permite reconhecer uma transição histórica e de época das formas sociais da sociedade disciplinar para a sociedade de controle. A sociedade disciplinar é aquela na qual o comando social é construído mediante uma rede dispersa de dispositivos que produzem e regulam os costumes, os hábitos e as práticas produtivas. Por meio de instituições disciplinares (prisão, fábrica, hospital, escola, universidade) que fornecem explicações lógicas para a razão da disciplina, essa sociedade põe para funcionar mecanismos de inclusão e de exclusão. A sociedade de controle desenvolve mecanismos cada vez mais democráticos, distribuídos pelos corpos (em sistemas de bem-estar, atividades monitoradas) e cérebros (em sistemas de comunicação, redes de informação) dos cidadãos. Essa sociedade pode ser caracterizada pela intensificação e síntese dos aparelhos de normalização e 


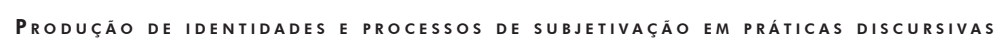

de disciplinarização. Exemplo disto é a ditadura do bem-estar, da beleza; é a obrigatoriedade de ser feliz segundo padrões já testados e definidos.

Acompanhando essa modernização dos mecanismos disciplinares, Foucault (2001) analisa que a hipótese da repressão cedeu lugar ao biopoder. $\mathrm{Na}$ concepção da hipótese repressiva, segundo Rabinow e Dreyfus (1995), há a ideia de que a resistência à repressão seria uma batalha importante e de que a voz transgressora desafiaria o poder repressivo, pois a oportunidade "de falar contra os poderes, dizer a verdade e prometer prazer; ligar entre si a iluminação, a libertação e volúpias múltiplas; manter um discurso onde se juntam o ardor do saber, a vontade de mudar a lei e o jardim esperado de delícias" (FOUCAULT, 2001, p.13) seria a forma de restabelecer a verdade distorcida pelo poder. Pode-se refletir, com base no biopoder, que a hipótese da repressão e a busca por vencê-la possibilitaram a construção de estratégias mais sutis e eficazes para o exercício do poder.

Conforme Foucault (2001), seria necessário falar de biopoder para designar aquilo que faz entrar a vida e seus mecanismos no domínio dos cálculos explícitos e torna o podersaber um agente de transformação da vida humana. Nisto se vê a preocupação com o bem-estar em termos de necessidade e felicidade das pessoas e com novas técnicas para maximizar a vida. Analisando os dispositivos midiáticos, Hardt e Negri (2004) explicam que a comunicação de massa expressa o movimento de globalização e controla o sentido de direção do imaginário que percorre essas conexões comunicativas, ou seja, o imaginário é guiado e canalizado dentro da máquina de comunicação. $\mathrm{O}$ poder, enquanto produz, organiza, e enquanto organiza, fala e se expressa como autoridade. A linguagem, à medida que comunica, 
produz mercadorias, mas, além disso, cria subjetividades, põe umas em relação às outras e as ordena.

A trajetória analítica de Foucault possibilita dizer que a questão da vida atravessa toda a sua obra, visto que ele a problematiza em vários ângulos. Portocarrero (2008) pensa da mesma forma e argumenta que essa problematização se deu primeiro por meio das análises das formas de objetivação do sujeito, de um lado, pela via da pesquisa arqueológica das condições de possibilidade da existência de saberes empíricos que propiciaram a constituição das ciências humanas tendo a vida e o homem como objetos, e por outro, pela via da genealogia dos poderes. Também afirma que as ciências biológicas se articulam com outros campos de saber e de práticas e com as relações de forças que incidem sobre a vida dos indivíduos. Em segundo lugar, a problematização da vida ocorre em suas análises das formas de subjetivação, com a hipótese de que a ética exige a visão da vida como obra de arte, sendo o cuidado de si a possibilidade de transformar o ser mesmo do sujeito para ter acesso à verdade e estabelecer para si um modo de vida ético, belo e heroico.

Inserida nessa trajetória, a noção de biopolítica é formulada por Foucault (2001) para demonstrar que o poder passa a ser exercido por meio de controles precisos e regulações de conjunto e mecanismos de segurança, como forma de exigir mais vida e de aumentar e gerir essa vida. A constituição da biopolítica só é possível no contexto da invenção da vida biológica, da entrada da vida nas ideias e práticas políticas. Num sentido mais amplo, o biopoder é uma forma de normalizar a própria conduta da espécie, de regrar, manipular, incentivar e observar macrofenômenos como as taxas de natalidade e mortalidade, as condições sanitárias das cidades, o fluxo das infecções e contaminações, a duração e as condições da vida. As tecnologias do biopoder e os 

Pimeira parte :: Discurso biopolítica na sociedade de controle

que merece viver e aquela que pode ser exterminada; instaura o corte entre a vida protegida e a vida abandonada e relegada à esfera marginal que fica fora do núcleo da comunidade política, a qual, estando banida, pode ser capturada e morta. É assim que se podem analisar essas relações nas campanhas estatais: alguns devem morrer para se tornarem estatísticas calculadas pelo poder-saber e reinscritas como agentes de transformação da vida para o convencimento de outros que devem viver.

Assim, a vida da população é regrada por enunciados que invadem todos os espaços da convivência social. As proibições aumentam a cada dia em conformidade com o desejo de viver mais e melhor, dentro de padrões estabelecidos pelos saberes e em conformidade com os problemas advindos das inovações científicas e tecnológicas. O biopoder é exercido de forma sutil, quase imperceptível, e produz comportamentos que o propagam e que aguardam por técnicas mais eficientes em garantir a vida. Produz, também, os culpados, os indolentes, que não quiseram perceber que a ciência, as novas tecnologias, os governos e a mídia investem na divulgação de saberes cujo objetivo é apenas melhorar e prolongar a vida da população. Desta forma, o poder estatal tem na própria população uma grande aliada no seu afã de garantir o sucesso de suas propagandas e promover a "caça às bruxas" que teimam em contaminar os normais. Produz-se a política da intransigência para com os que se negam a passar pela purificação. É o que se vê nas campanhas voltadas aos cuidados com a forma física e com a alimentação, à erradicação dos vícios, ao controle das atividades sexuais, à violência urbana, etc.

Em uma entrevista publicada em 1977 em Microfísica do poder, intitulada "Não ao sexo rei", Foucault (2003) esclarece que o discurso da liberação sexual promovido pelos sexólogos colocava uma armadilha perigosa, pois funcionava como um 
Produçäo de identidades e processos de subjetivaçäo em práticas discursivas

instrumento de controle e de poder ao utilizar o que as pessoas diziam, sentiam ou esperavam. Esse tipo de discurso explora a tentação de acreditar que, para ser feliz, basta ultrapassar o umbral do discurso e eliminar algumas proibições. Além disso, acaba depreciando e esquadrinhando os movimentos de revolta e liberação e produzindo uma forma de proibição ainda mais eficiente: a ordem do discurso. Em suas elaborações sobre o biopoder Foucault esteve alerta a essa ordem para evidenciar que as políticas higienistas e saneadoras levam a população a louvar o espírito humanitário das intervenções políticas que visam a incentivá-la, protegê-la, estimular e administrar a sua vida, e a não perceber a contrapartida brutal dessa obsessão do poder estatal pelo cuidado purificador da vida. Mesmo tendo a vida se constituído no elemento político que precisa ser normalizado, a violência não foi controlada, pois tal cuidado com a vida traz a exigência contínua da morte em massa, já que é no contraponto da violência purificada que se podem garantir melhores formas de sobrevivência a uma dada população.

Dessa forma, o biológico, ao incidir sobre o político, faz com que o poder já não se exerça sobre sujeitos de direito, cujo limite é a morte, mas sobre seres vivos, de cuja vida o poder deve se encarregar. Conforme Foucault (2001, p. 136), "foi a vida, muito mais do que o direito, que se tornou o objeto das lutas políticas, ainda que estas últimas se formulem através da afirmação de direito". É a vida que também norteará a história da linguística como uma saída para o caráter prescritivo e sistematizado da língua, que não a contemplava em sua exterioridade e em sua manifestação opaca e diferenciada e decretava, como um soberano, a morte daquilo que escapava à normatividade e ao sistema. A saída para a garantia do exercício do poder, da mesma forma que em outras formações discursivas, era deixar viver a língua 
Pimeira parte :: Discurso e biopolítica na sociedade de controle

em suas manifestações, mas fazê-lo utilizando-se de formas de higienização justificadas pelo caráter humanitário que invadirá as relações humanas. O poder político passa, principalmente, pelas concepções de língua, e atribui a esta um caráter conforme com suas estratégias para governar.

Gadet e Pêcheux (2004), para situar o discurso na história da linguística, traçam um paralelo entre o direito e a vida para demonstrar a linha - ora pendular, ora espiral - que será seguida pela linguística entre o pensamento lógico e os ideais sociológicos. Argumentam que a lógica garante o exercício do direito numa ditadura que assegura a disjunção entre o lícito e o criminoso, o legítimo e o ilegítimo, o válido e o não válido, o verificável e o falso. Essa lógica ancora-se, conforme os autores, na escrita lógico-matemática. A noção de vida, de caráter biológico, estende uma rede descritiva sobre a diversidade das línguas e dialetos para mostrar o conjunto de suas diferenças, fazendo com que a linguística construa sua versão funcionalista como ferramenta para resolver os problemas sociais. Analisando a Modernidade capitalista, os referidos autores (p. 116) assim se expressam:

\footnotetext{
[...] marcada pela lógica da administração (a língua de madeira do Estado) e pela "língua de vento" da propaganda, [é] que a linguagem foi instituída como "instrumento de comunicação"... dissimulando pela noção higiênica da informação o fato de que o que se comunica provém de uma loucura do Estado: a era dos comunicados é, ao mesmo tempo, a da comunicação das ordens e da dos delírios comunicados.
}

O sociobiologismo, conforme Gadet e Pêcheux, tem seu desenvolvimento marcado pelas técnicas de higienização da língua e acaba alcançando o que hoje se conhece como o politicamente correto, que serve aos interesses do biopoder para disseminar as ideias da qualidade de vida em suas várias esferas. Como integrante da política da vida, o politicamente correto 
Produçäo de identidades e processos de subjetivaçäo em práticas discursivas

classifica e identifica as pessoas incluindo-as numa normalidade forjada e excluindo o que pretendia incluir. No processo de democratização das práticas sociais e da língua como instrumento, a padronização será exigida não pelo viés autoritário das leis e regras do Direito ou das gramáticas, mas pelo viés da necessidade difundida de se ter qualidade de vida, acesso a mecanismos que possam garantir o prolongamento da vida e o direito de ocupar o lugar do diferente, mas de uma diferença que é justificada e categorizada por contextos sociais e culturais. A relação causal entre contexto e linguagem, contexto e atitudes e contexto e comportamento produz outra espécie de classe, que não pode ser excluída, mas pode ser instigada a ocupar o lugar dos bemsucedidos, dos saudáveis física e emocionalmente, dos belos, dos conectados nas informações - dos felizes, enfim.

Como a língua é o lugar da falha, do ambíguo, que nem a lógica nem a sociologia - em parceria com a biologia, a filantropia e o espírito humanitário - puderam prever em regras ou categorizar em conjuntos fechados e homogêneos de diferenças, o seu efetivo uso, os ditos constitutivos do biopoder, sofrem a força da contradição, pois, ao mesmo tempo em que produzem as normalizações e incitam à ação medida e avaliada previamente pelos saberes, produzem também acontecimentos não planejados nem previstos pelos conhecimentos difundidos. Assim é que, ao lado das práticas que almejam o bem-estar, surgem outras práticas que acabam promovendo, por exemplo, a incidência de outras doenças na situação de uma doença que está sendo combatida, como é o caso das campanhas contra a obesidade, as quais, pela insistência em associar a magreza à saúde, ajudam a produzir a anorexia, a bulimia, etc. É o caso, da mesma forma, do desemprego imposto ao fumante pelo fato de muitas empresas, fábricas e indústrias não mais aceitarem fumantes em seus quadros 
Pimeira parte :: Discurso biopolítica na sociedade de controle

de trabalhadores. O fechamento de estabelecimentos que não obedecem à lei do silêncio, a qual visa à garantia do sossego das pessoas, mas determina a exclusão, pela perda do trabalho, de vários tipos de profissionais. Outras práticas vão sendo criadas por aqueles que, de alguma forma, resistem às estratégias do biopoder. $\mathrm{Na}$ atualidade, pode-se assistir a certas mudanças nos hábitos dos brasileiros, como reunir amigos e beber em casa para escapar da lei seca, o que significa o fechamento de bares e restaurantes; ou fumar nas calçadas dos bares sob sereno, chuva, o que também pode provocar doenças, criando um novo lugar de encontro de pessoas para uma conversa; e ainda explorar os idosos, os quais, depois que alcançaram a "melhor idade", são convocados a consumir várias espécies de produtos para serem felizes e eternos.

Os enunciadosque constroem obiopoderacabam efetuando alguns "tiros que saem pela culatra", provocando a intransigência de alguns em relação a outros, a discriminação daqueles que não se encaixam nas normas do corpo magro, sadio, bonito, feliz. Prova disso é o grande aumento do estado de depressão numa época em que se encontram em todos os lugares as fórmulas para ser feliz. Como afirma Foucault (2004), a felicidade não é mais somente um simples efeito, a felicidade dos indivíduos é uma necessidade para a sobrevivência e o desenvolvimento do Estado. [...] A felicidade dos homens se torna um elemento do poderio do Estado.

Nessa expectativa constante de felicidade, as pessoas clamam por mais regras, mais proibições, vigilância e punição. Cobram segurança e policiamento, exigem câmeras de vigilância, trocando a privacidade pela aparente segurança e aceitando o risco de essa tecnologia ser usada para fins que podem virar-se contra as mesmas pessoas que a pedem. 
O exercício do biopoder é tão eficiente que se torna quase impossível pensar numa forma de resistência que de fato possa funcionar. Foucault fala do cuidado de si, de uma ética da bela existência; mas difundir uma ética de reflexão num mundo em que a moral comanda até mesmo as decisões políticas de saúde, ou em que a lei é a medida do que pode ser feito, não importando outras consequências, torna-se uma utopia diante das comprovações verificáveis da ciência e acatadas pela Justiça. Foucault propõe uma reflexão em torno da morte e da vida nas relações de poder. Se o biopoder é exercido tomando a vida como estratégia, a resistência só poderia ocorrer com a perda do medo da morte - medo que leva uma parte da população a desejar exterminar a outra parcela desta mesma população, como forma de garantir a própria sobrevivência, longevidade e - quem sabe - a possibilidade de se tornar eterna.

\section{Referências}

DUARTE, A. Biopolítica e resistência: o legado de Michel Foucault. In: RAGO, M.; VEIGA-NETO, A. Figuras de Foucault. Belo Horizonte: autêntica, 2008.

FOUCAULT, M. Vigiar e punir: nascimento da prisão. Petrópolis: Vozes, 1987. . A arqueologia do saber. Rio de Janeiro: Forense Universitária, 1995 a. - A arqueologia do saber. Rio de Janeiro: Forense Universitária,1995. . A verdade e as formas jurídicas. Rio de Janeiro: Nau Ed., 1996. Em defesa da sociedade. São Paulo: Martins Fontes, 1999.

54 
Pimeira parte :: Discurso biopolítica na sociedade de controle

Sobre as maneiras de escrever a história. In: MOTTA, M. B. da (org.) Foucault: arqueologia das ciências e história dos sistemas de pensamento. Ditos e Escritos II. Rio de Janeiro: Forense Universitária, 2000.

História da sexualidade I: a vontade de saber. Rio de Janeiro: Graal, 2001.

A governamentalidade. In: MOTTA, M. B. da (org.) Foucault: estratégia, poder-saber. Ditos e Escritos IV. Rio de Janeiro: Forense Universitária, 2003.

Microfísica do poder. Rio de Janeiro: Graal, 2003.

A tecnologia política dos indivíduos. In: MOTTA, M. B. da (org.)

Foucault: Ética, sexualidade, política. Ditos e Escritos V. Rio de Janeiro: Forense Universitária, 2004.

GADET, F.; PÊCHEUX, M. A lingua inatingivel. Campinas-SP: Pontes, 2004.

HARDT, M.; NEGRI, A. Império. Rio de Janeiro: Record, 2004.

PELBART, P. P. Vida capital: ensaios de biopolitica. São Paulo: Iluminuras, 2003.

PORTOCARRERO, V. os limites da vida: da biopolítica aos cuidados de si. In: ALBUQUERQUE JÚNIOR, D. M.; VEIGA-NETO, A.; SOUZA FILHO, A.; Cartografias de Foucault. Belo Horizonte: Autêntica, 2008.

RABINOW, P.; DREYFUS, H. Michel Foucault: uma trajetória filosófica - para além do estruturalismo e da bermenêutica. Rio de Janeiro: Forense Universitária, 1995. 
